\title{
The sweet cake that reaches parts other cakes can't!
}

\author{
R M Hussain
}

Postgrad Med J 2003;79:1 15-1 16

This is a case report of a previously healthy woman of 56 years who presented with a life threatening tetraparesis, severe hypokalaemia, hypertension, and raised muscle enzymes. The cause of was finally found to be unusual and very much "local". Initial inquiry into her drug history was negative until she was made aware that herbal remedies could cause serious adverse reactions. She then mentioned that she had been eating a large number of "Pontefract cakes" (a liquorice sweet) for the management of her chronic constipation. This case highlights the importance of asking about herbal remedies when taking a drug history in all patients, including those admitted as medical emergencies.

A 56 year old woman presented with flu-like symptoms, which she had for seven days. She also had nausea, vomiting and diarrhoea, followed by generalised weakness, which rendered her bedbound, necessitating emergency hospital admission. She denied any history of pyrexia, cough, sore throat, shortness of breath, or haemoptysis. There was no history of headache or visual and sensory disturbances. She had not been on any recent foreign travel.

Her past medical history consisted of longstanding backache, which had been fully investigated. Investigations included magnetic resonance imaging which showed extensive disc and facet degenerative disease with moderate canal stenosis of lumbar $4 / 5$ vertebra for which she was on regular, simple analgesia. She was also on topical capsacin cream and indicated that she had chronic constipation for which she was on regular lactulose and a bulk forming laxative (Fybogel R\&C). She was a non-smoker and drank alcohol socially.

Clinical examination showed she was hypertensive (blood pressure $170 / 90 \mathrm{~mm} \mathrm{Hg}$ ), in sinus rhythm (heart rate 99 beats/min), with a temperature of $36.8^{\circ} \mathrm{C}$, and oxygen saturation of $99 \%$. Examination of her cardiovascular and respiratory systems and of the abdomen was normal. There was striking global weakness, grade $1 / 5$, mainly in the shoulder and pelvic girdle muscles with normal reflexes, sensory system, cranial nerves, and sphincters.

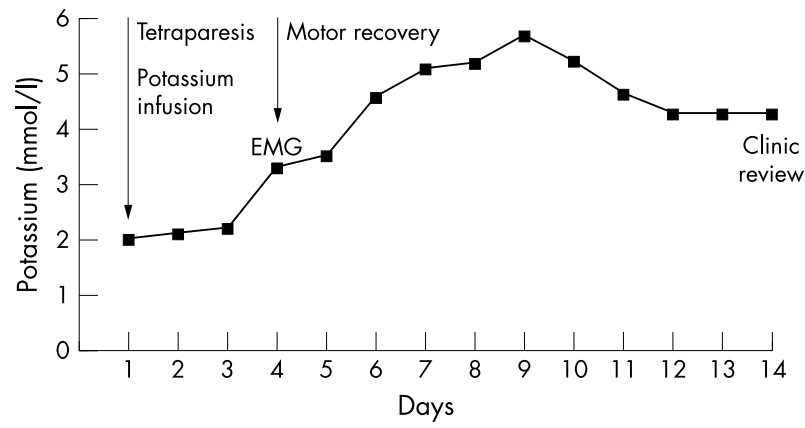

Figure 1 Serum potassium concentration over time. $E M G$, electromyography.
Laboratory investigations revealed a haemoglobin of $145 \mathrm{~g} / \mathrm{l}$ (normal range $115-165)$, white cell count $9.8 \times 10^{9} / 1(4-11.0)$, neutrophils $6.03 \times 10^{9} / 1$, platelets $474 \times 10^{9} / 1(150-400)$, erythrocyte sedimentation rate $12 \mathrm{~mm} /$ hour (1-14), C-reactive protein $16 \mathrm{mg} / \mathrm{l}(0-9)$, infectious mononucleosis screen was negative, prothrombin time $13.7 \mathrm{sec}(12.0-16.0)$, international normalised ratio 1.1, activated partial thromboplastin time $27.5 \mathrm{sec}(26-38.0)$, serum sodium $144 \mathrm{mmol} / \mathrm{l}$ (136-145), potassium $2.2 \mathrm{mmol} / \mathrm{l}(3.5-5.0)$, urea $4.7 \mathrm{mmol} / \mathrm{l}(2.5-6.0)$, creatinine $76 \mathrm{mmol} / \mathrm{l}(60-120)$, blood glucose $4.6 \mathrm{mmol} / \mathrm{l}$ (3-7.8), magnesium $0.9 \mathrm{mmol} / \mathrm{l}(90-120)$, albumin $40 \mathrm{~g} / \mathrm{l}$ (35$50)$, alkaline phosphatase $147 \mathrm{U} / \mathrm{l}(40-120)$, alanine transaminase $415 \mathrm{U} / \mathrm{l} \quad(0-56)$, bilirubin $28 \mu \mathrm{mol} / \mathrm{l} \quad(0-22)$, $\gamma$-glutamyltransferase $66 \mathrm{U} / \mathrm{l}(0-58)$, creatine kinase $18000 \mathrm{U} / \mathrm{l}$ (0-200), troponin I $1.0 \mathrm{ng} / \mathrm{ml}(0-2)$, vitamin B12 $538 \mathrm{pg} / \mathrm{ml}$ (160-1130), red cell folate $346 \mathrm{ng} / \mathrm{l}$ (120-860), free thyroxine $20.8 \mathrm{pmol} / \mathrm{l}(10-25.0)$, and thyroid stimulating hormone 0.5 $\mathrm{ml} \mathrm{U} / \mathrm{l}(0.2-4.00)$. Blood cultures were negative and she had normal chest radiography, abdominal ultrasound, computed tomography of the head, and electromyography.

Autoantibodies and anticholinestrease antibodies were negative. A viral screen for adenovirus, Coxsackie, influenza A, and influenza B was negative and so was screening for mycoplasma, psittacosis, Q fever, and parvovirus.

A diagnosis of severe hypokalaemic myopathy with pseudoaldosteronsim was made. We considered different possible causes like a viral illness complicated by nausea and vomiting leading to hypokalaemia and abnormal liver function tests, polymyositis, hypokalaemic periodic paralysis, thyrotoxic muscular paralysis, and myasthenia gravis.

Her life threatening hypokalaemia was corrected with intravenous potassium chloride, under close monitoring. Her serum potassium (fig 1) and creatine kinase concentrations (fig 2) and liver function tests returned to normal within a few days, coinciding with full motor recovery.

Initial inquiry into drug history was negative. However, when we made her aware that herbal remedies could cause serious adverse reactions, she mentioned that she had been using "Pontefract cakes" (a liquorice sweet) for the management of her chronic constipation. She was taking 200-400 g of the sweet daily; this is a large amount that equates to a dose of $15 \mathrm{~g}$ of pure liquorice.

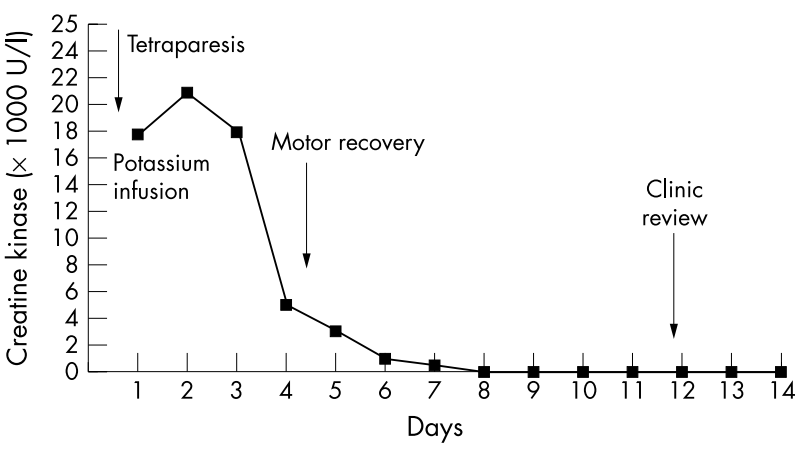

Figure 2 Creatine kinase concentration over time. 


\section{What is already known on the subject}

- Liquorice has become a widely used additive in various foods and drugs.

- It can cause severe hypokalaemia, leading to serious complications.

- Severe hypokalaemia can cause life threatening rhabdomyolysis.

\section{What this case report adds}

- Herbal medicines are used by many members of the public.

- Pontefract cake is used by some as a laxative.

- Drug history, including herbal medicines, is an invaluable part of good history taking.

- Patients on diuretics and the elderly must be made aware of the risk of liquorice over-consumption and that it can cause life threatening problems.

After discharge, she remained well and when reviewed two weeks later, she was found to be normotensive and normokalaemic and had stopped eating Pontefract cakes.

\section{DISCUSSION}

Glycyrrhizin, the major component of glycyrrhiza (liquorice) root, has a steroid structure which induces the retention of sodium and water and increases potassium excretion. ${ }^{12}$ It has long been known that liquorice contains significant quantities of glycyrrhizinic acid, a metabolite of which, glycyrrhetenic acid, inhibits renal $11 \beta$-hydroxysteroid dehydrogenase (11 $\beta$ HSDH), an enzyme present in the aldosterone receptor cells of the cortical collecting duct. ${ }^{3}$ Cortisol and aldosterone are structurally related and can bind to the aldosterone receptor with equal affinity.

Cortisol is normally prevented from receptor binding because $11 \beta-H S D H$ converts cortisol into inactive cortisone before it can enter cells. When $11 \beta-\mathrm{HSDH}$ is inhibited by glycyrrhizinic acid, cortisol escapes inactivation and binds to the aldosterone receptor, thus exerting an aldosterone-like effect. $^{4}$

Liquorice is an old remedy that was used by Egyptians and Assyrians BC. It is widely used in Chinese medicine and as a sweetener in drugs, foods, and drinks in various part of the world. The monks first introduced it into Pontefract, West Yorkshire, UK, in 1562 and George Dunhill, a local chemist, added sugar to it and named it Pontefract cake.

Liquorice ingestion has been reported in the literature to cause a variety of problems including hypertension and hypertensive encephalopathy, ${ }^{5}$ due to apparent mineralocorticoid excess, ${ }^{6}$ life threatening hypokalemia, ventricular tachycardia, ${ }^{7}$ and critical limb ischaemia. ${ }^{8}$ It has also long been known that liquorice can induce hypokalaemic myopathy and myoglobinuria. ${ }^{9}$

The amount of liquorice ingested by patients presenting with hypokalaemic myopathy appears to vary between $150 \mathrm{mg}$ and $250 \mathrm{mg}$ daily. ${ }^{6}$ The issues of the quantity and duration of liquorice ingestion were tested in a recent study to clarify the dose-response and the time-response relationship between liquorice ingestion and the rise in blood pressure, exploring interindividual variance. Volunteers consumed liquorice in various doses, ranging from 50-200 g/day, for 2-4 weeks, equivalent to a daily intake of $75-540 \mathrm{mg}$ of glycyrrhetenic acid, the active substance in liquorice. Blood pressure rose by 3.1-14.4 $\mathrm{mm} \mathrm{Hg}$, showing a linear dose-response relationship. ${ }^{10}$

One final comment. I would very much like to see all manufacturers of such apparently innocent substances label and highlight the potential risks in over-consumption, to avoid a case like this, which was potentially life threatening. Too much of a sweet thing is not always simply having it too sweet!

\section{Author's affiliation}

R M Hussain, Integrated Department of General Medicine, Pontefract General Infirmary, Friarwood Lane, Pontefract, West Yorkshire WF8 1PL, UK

Correspondence to: Dr Hussain; raja.hussain@panp-tr.northy.nhs.uk

Submitted 2 December 2002

Accepted 5 December 2002

\section{REFERENCES}

1 Conn JW, Rovner DR, Cohen EL. Liquorice induced pseudohyperaldosteronism. Hypertension, hypokalemia, aldosternopenia and suppressed plasma rennin activity. JAMA 1968:205:492-6.

2 Kraus SD. Deoxy corticosterone-mimetic action of ammoniated glycyrrhizin in rats. J Exp Med 1957;106:415-22.

3 Stewart PM, Wallece AM, Valentino R, et al. Mineralocorticoid activity of liquorice: 11 -beta-hydrogenase deficiency comes of age. Lancet 1987; ii:821-5

4 Edward CRW. Lessons from liquorice. N Engl J Med 1991;24:1242-3.

5 Russo S, Mastropasqua M, Moseetti MA, et al. Low dose of liquorice can induce hypertensive encephalophthy. Am J Nephrol 2000:20:145-8.

6 Walker BR, Edward CR. Liquorice induced hypertension and syndrome of apparent mineralocoticoid excess. Endocrinol Metab Clin North Am 1994;23:359-77.

7 Eriksson JW, Carlberg B, Hillorn V. Life threatening ventricular tachycardia due to liquorice-induced hypokalaemia. J Intern Med 1999:245:307-10

8 Lanazo P, Flores D, Martinez S, et al. Upper limb induced by liquorice ingestion. J Cardiovasc Surg 2000;41:631-2.

9 Gross EA, Dexter JD, Roth RG. Hypokalaemic myopathy with myoglobinuria associated with liquorice ingestion. N Engl J Med 1966:274:602-6

10 Sigurionsnsdottir HA, Franzon L, Manhem K, et al Liquorice-induced rise in blood pressure linear dose-response relationship. J Hum Hypertens $2001 ; 15: 549-52$ 